\title{
Kompetisi Industri Transportasi: Tinjauan Komunikasi Pemasaran Jasa PT Kereta Api Indonesia
}

\author{
Prima Mulyasari Agustini
}

\begin{abstract}
The development of transportation industry has removed the train business from its monopolistic business. Sooner or later, the government will open up opportunity for private parties to participate in the train business. In order to successfully anticipate this future, PT Kereta Api Indonesia (KAI) needs to change its communication strategy. Integrated Service Marketing Communication (ISMC) was recommended as a strategic approach covering management of service promise, management of customer expectation, customer education improvement, and management of internal marketing communication.
\end{abstract}

Kata kunci: komunikasi pemasaran, jasa, terpadu, PT Kereta Api Indonesia.

\section{Jasa PT Kereta Api Indonesia}

Kehadiran PT. Kereta Api Indonesia (PT. KAI) tidak dapat dilepaskan dari Proklamasi Kemerdekaan Republik Indonesia. Tepatnya, pada 28 September 1945, karyawan KA yang tergabung dalam “Angkatan Moeda Kereta Api” (AMKA) mengambil alih kekuasaan perkeretaapian dari pihak Jepang. Sejak itulah kekuasaan perkeretaapian berada di tangan bangsa Indonesia (www.keretaapi.com).

Perubahan status dari Perumka menjadi PT. KAI pada 1 Juni 1999, menandai sejarah baru perkembangan perkeretaapian di Indonesia, di mana mereka mulai memperhatikan aspek bisnis, walaupun tetap memiliki misi sosial. PT. KAI mulai mengalami perkembangan yang cukup pesat pada tahun 1994, sejak dikembangkannnya kereta api komersial seperti Parahyangan, Argo Bromo, Argo Gede, dan Argo Anggrek.

Guna mempertahankan pelanggan kereta api, dengan adanya substitusi alat transportasi lain, seperti maskapai penerbangan dan travel, beberapa langkah yang diambil oleh PT. KAI adalah:

(a) Penetapan harga tiket berdasarkan hari. Sejak April 2004, harga tiket dibedakan berdasarkan waktu-waktu tertentu. Untuk peak season (Jumat-Minggu) harga tiket ditetapkan lebih tinggi dari pada low season (Senin-Kamis).

(b) Sistem zonasasi. Dengan sistem ini, penumpang membayar tiket sesuai stasiun tujuannya.

(c) Ticketing di Internet. Dalam rangka peningkatan pelayanan, KAI menyediakan informasi harga tiket, jadwal keberangkatan, 
pemesanan, dan informasi lainnya melalui fasilitas Internet.

(d) Fasilitas layanan pesan-antar. KAI berencana memberikan layanan berupa jasa pengantaran tiket ke rumah pelanggan.

(e) Konsentrasi pada rute-rute jarak dekat. KAI menambah dan mengembangkan rute-rute kereta api bisnis dan eksekutif jarak dekat melalui kerjasama dengan pihak lain, termasuk Pemerintah Daerah.

(f) Peningkatan pelayanan. KAI mengupayakan pelayanan standar minimum pada semua kelas KA: Ekonomi, Bisnis, dan Eksekutif.

\section{Kompetitor PT KAI di Industri Transportasi}

\subsection{Industri Angkutan Udara}

Sejak Departemen Perhubungan melakukan deregulasi peraturan di sektor transportasi udara, maskapai penerbangan baru bermunculan. Bahkan, beberapa di antaranya memilih strategi murah (lowcost airlines). Dalam hal ini, maskapai penerbangan mencoba memanfaatkan peluang pasca dicabutnya aturan batas bawah dalam penetapan tarif penerbangan yang dilakukan pemerintah. Dengan harga yang murah, mereka berlomba mendapatkan penumpang sebanyak mungkin, dalam kondisi di mana sebagian besar penumpang Indonesia memang sangat sensitif terhadap harga.

Dengan situasi pasar seperti ini, PT. KAI mulai memiliki pesaing yang sangat kuat, karena jasa penerbangan dan jasa kereta api merupakan substitusi satu sama lain. Murahnya tarif penerbangan mengancam posisi PT KAI. Sementara, di sisi lain, waktu tempuh kereta api dengan pesawat untuk rute yang sama, sangat jauh berbeda.

Murahnya tarifangkutan udara menyebabkan munculnya persaingan ketat antarmaskapai penerbangan yang berusaha menetapkan harga yang murah dan terjangkau. Dalam hal ini jelaslah konsumen yang diuntungkan. Maskapai yang tidak mampu bersaing akan memilih keluar dari industri ini. Dampak kompetisi ini tidak saja menimpa sesama maskapai penerbangan, namun berdampak pada industri transportasi lainnya seperti kereta api, bis, atau kapal laut.

Rute yang mendapatkan tantangan terberat dengan adanya kebijakan baru mengenai penentuan tarif maskapai penerbangan adalah rute JakartaSurabaya. Jalur ini biasanya dilayani oleh Kereta Api "Argo Anggrek." Namun, saat ini begitu banyak maskapai penerbangan menawarkan biaya yang hanya terpaut sedikit dengan "Argo Anggrek," dengan waktu tempuh yang terpaut jauh. Dengan pesawat, rute ini dapat ditempuh tidak lebih dari 1 jam 15 menit. Bandingkan dengan waktu tempuh kereta api yang bisa mencapai 12 jam!

\subsection{Industri Angkutan Darat}

Seiring dengan peningkatan pembangunan di sektor transportasi, pemerintah membangun ruasruas jalan yang mempersingkat waktu tempuh melalui jalur darat, seperti Tol Cipularang. Hal ini juga membawa dampak bagi industri perkeretaapian. Apalagi dengan pembangunan jalan tol, waktu tempuh bisa dipersingkat hingga setengahnya. Sebagai contoh: waktu tempuh Bandung-Jakarta, biasanya mencapai 4-5 jam; melalui Tol Cipularang dapat ditempuh hanya dengan waktu 2 jam. Apalagi, saat ini banyak sekali perusahaan travel yang membuka jalur-jalur yang dapat ditempuh melalui tol, dengan harga yang kompetitif. "Baraya Travel" (Bandung), misalnya, mematok harga Rp 35.000, untuk perjalanan Bandung-Jakarta, sementara tarif kereta api "Argo Gede" dibandrol Rp 70.000. Waktu tempuh "Baraya Travel" sendiri hanya sekitar 2,5 jam, sementara "Argo Gede" bisa mencapai empat jam.

Rute perjalanan yang mendapatkan tantangan terberat adalah Bandung-Jakarta. Dengan menggunakan jasa travel minibus atau bis, waktu tempuhnya tidak lebih dari 2,5 jam. Sementara, dengan menggunakan "Argo Gede," waktu tempuh bisa mencapai 4 jam. Apalagi harga yang dibandrol KAI mencapai Rp 70.000. Sementara, berkendaraan dengan travel atau bis, biayanya tak lebih dari Rp 60.000 , bahkan ada yang berani mengenakan tarif tak lebih dari Rp 30.000. 


\subsection{Urgensi Deregulasi Perkeretaapian di Indonesia}

Tingginya kompetisi di industri transportasi memaksa PT. KAI menciptakan competitive advantage dan superior customer value, yang akan diperoleh pelanggan apabila menggunakan jasa KAI. Agar mampu berkompetisi, PT. KAI yang selama ini dikenal sebagai satu-satunya perusahaan milik pemerintah yang bergerak dalam jasa perkeretaapian, mestinya perlu membuka diri sebagai perusahaan yang tidak melakukan monopoli. Regulasi pemerintah kelihatannya perlu memberikan angin bagi pihak swasta yang ingin meramaikan bisnis di bidang jasa perkeretaapian ini. Dibukanya kran bisnis di bidang ini akan membuat siapa pun berupaya untuk memberikan pelayanan terbaik dengan harga yang kompetitif.

Deregulasi di bidang perkeretaapian, di sisi lain, diharapkan dapat mengundang banyak investor, sehingga, pada saatnya nanti, Indonesia akan memiliki kereta api yang diklaim tercepat di dunia, seperti TGV (Prancis) dan Shinkansen (Jepang). Berkat dana investor yang akan mengalir, kereta api bawah tanah/subway pun dapat terwujud. Begitu pun dengan kemungkinan hadirnya monorel, yang akan kian meramaikan industri transportasi darat ini. Dengan bertambahnya moda alternatif untuk mengangkut penumpang maupun barang dari satu tempat ke tempat lainnya, simpul-simpul yang selama ini menjadi penghambat distribusi barang akan diputus.

Bisnis perkeretaapian juga akan mengalami kompetisi seperti yang terjadi dalam bidang jasa penerbangan, di mana pelanggan pesawat ingin sampai di tempat tujuan dengan cepat, aman, dan selamat, ditambah dengan biaya yang terjangkau. Naik kereta api tidak akan lagi dipandang kurang prestise, mau dilayani seadanya, bahkan seringkali tidak tepat waktu. Dengan kompetisi yang ada, siapa pun yang masuk ke dalam industri ini bakal berusaha untuk memberikan added value bagi para pengguna jasanya.

\section{Bagaimana Mengomunikasikan Jasa PT KAI?}

Begitu hiruk-pikuknya market dengan moda transportasi, sehingga pelanggan dibanjiri berbagai informasi pemasaran, yang akan menggiring pelanggan untuk melakukan keputusan pembelian. PT. KAI dalam hal ini perlu mendorong pembelian pelanggan pada titik yang tepat, tapi tidak menjerumuskan, bahkan membohongi pelanggan. Dengan komunikasi pemasaran yang tepat, PT. KAI dapat menemukan saluran untuk merebut kembali kejayaan yang dulu pernah dicapai, yaitu sebagai alat transportasi yang paling didambakan masyarakat. Kepuasan dan loyalitas pelanggan merupakan sesuatu yang sangat mungkin dicapai.

Berbeda dengan konsep komunikasi pemasaran konvensional, Zeithaml dan Bitner (2003:447) menyatakan, dalam komunikasi pemasaran jasa, perusahaan jasa harus menambahkan konsep komunikasi pemasaran tradisional atau promotion mix yang terfokus pada bagaimana cara pelanggan menerima informasi tentang jasa, melalui:

(1) Komunikasi Pemasaran Eksternal (External Marketing Communication), yaitu kegiatan komunikasi pemasaran di mana penyampaian pesan dari perusahaan kepada pelanggan melibatkan saluran komunikasi tradisional, seperti advertising, sales promotion, public relations, dan direct marketing.

(2) Komunikasi Pemasaran Internal (Internal Marketing Communication), yaitu kegiatan komunikasi di mana manajemen mengajak penyedia jasa untuk meningkatkan kemampuan dalam mengirimkan jasa melalui perekrutan, pelatihan, motivasi, ganjaran, dan penyediaan alat serta teknologi. Jika karyawan jasa tidak mampu menyampaikan jasa yang telah dijanjikan kepada pelanggan, maka perusahaan akan gagal. Komunikasi pemasaran internal dapat dilakukan dengan dua cara, yaitu vertical communication dan horizontal communication.

(3) Pemasaran Interaktif (Interactive Marketing 


\section{Gambar 1}

\section{"Communications and the Services Marketing Triangle"}

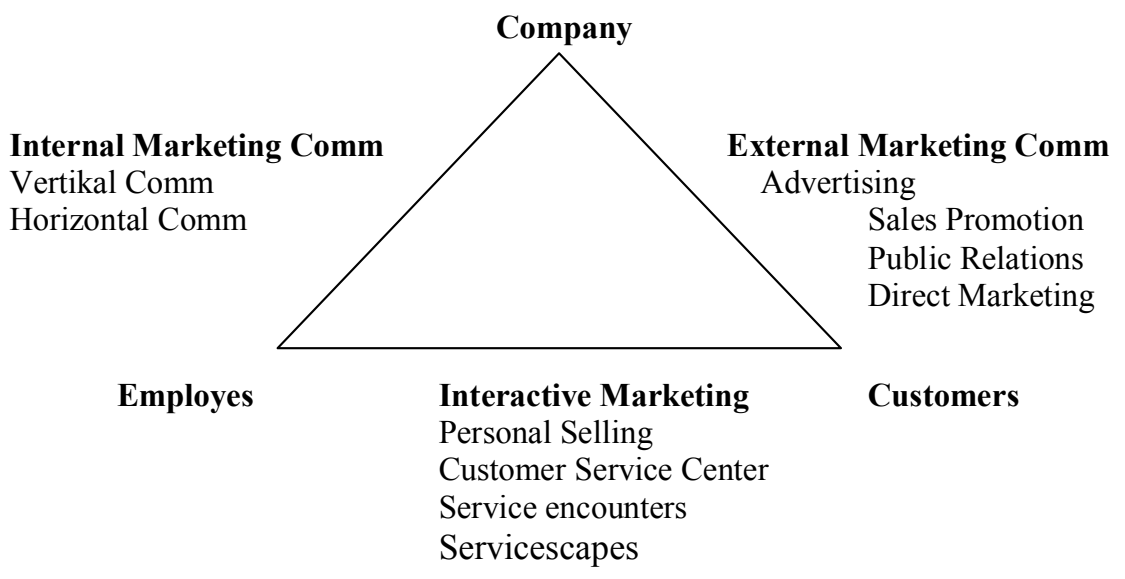

Sumber: Zeithaml dan Bitner, (2003)

Communication), melibatkan pesan dari karyawan yang diberikan kepada pelanggan melalui saluran seperti personal selling, interaksi customer service, interaksi service encounter, dan servicescape. Karyawan yang dimaksud dalam komunikasi pemasaran interaktif adalah karyawan perusahaan, subkontrak, atau agen. Jika janji yang telah diberikan kepada pelanggan tidak dapat dipenuhi oleh karyawan, pelanggan bisa menjadi tidak puas dan seterusnya akan meninggalkan perusahaan.

Untuk lebih jelasnya, komunikasi pemasaran jasa dapat dilihat pada gambar 1 .

Segitiga Communications and the Services Marketing terdiri dari tiga elemen, yaitu:

\section{(1) External Marketing Communication}

(a) Advertising, atau periklanan, yang didefinisikan sebagai “....any paid form of non-personal-presentation and promotion of a company's offering by an identified sponsor" (Zeithaml dan Bitner, 2003: 449). Bentuk-bentuk advertising meliputi: iklan cetak dan radio, kemasan luar, kemasan sisipan, surat, katalog, film, majalah, booklet dan brosur, poster dan selebaran, buku alamat dagang, papan iklan, papan nama, pameran pembelian, materi audiovisual, simbol dan logo. PT. KAI dapat menggunakan bentuk-bentuk iklan tersebut untuk membantu PT. KAI memosisikan produknya di benak pelanggan.

(b) Sales Promotion, atau promosi enjualan, yaitu "... short-term incentives such as coupons, premiums, or discount that stimulate customer purchase" (Zeithaml dan Bitner, 2003: 449). Promosi penjualan dapat ditempuh PT. KAI dengan memberikan insentifjangka pendek, seperti kupon, premium, ataupun diskon guna mendorong pembelian konsumen.

(c) Public Relations atau lembaga/aktivitas hubungan masyarakat, yaitu “... building a favourable company image with firm's publics though publicity, relations with the news media and community events" (Zeithaml dan Bitner, 2003: 449). Kegiatan public relations perlu dilakukan sebagai salah satu upaya membentuk citra PT. KAI 
yang positif. Hal ini dapat dilakukan dengan membuat publisitas, menjalin hubungan baik dengan berbagai media, dan membuat event-event tertentu untuk membangun image yang favourable.

(d) Direct Marketing atau pemasaran langsung, yaitu "... the use of mail, telephone, fax, e-mail and other non-personal tools to communicate directly with specific consumers to obtain a direct response" (Zeithaml dan Bitner, 2003: 449). Pemasaran langsung dapat dilakukan PT. KAI agar perusahaan mendapatkan tanggapan langsung dari pelanggan, baik melalui surat langsung, telepon, fax, atau pun e-mail.

\section{(2) Interactive Marketing, berupa}

(a) Personal Selling, yaitu “...personal presentation by a representative form the firm to make sale and buy a customer relationship" (Zeithaml dan Bitner, 2003: 449). Penjualan personal merupakan bentuk komunikasi pemasaran yang paling klasik. Upaya ini bisa dilakukan agar terjadi proses jual-beli, antara KAI dengan pelanggan.

(b) Customer Service, yang persisnya adalah “... the service provided in support of a company's core product" (Zeithaml dan Bitner, 2003: 4). Customer service seringkali melibatkan aktivitas, seperti menjawab pertanyaan, menerima order, memberi persetujuan rekening tagihan, penanganan komplain, dan penjadwalan perawatan serta perbaikan. Customer service dapat melakukan kegiatannya, baik dengan duduk di kursi kerjanya, melakui telepon, atau pun internet. Bahkan banyak customer service pada perusahaan-perusahaan besar beroperasi 24 jam.

Kualitas customer service sangat penting dalam membangun hubungan baik dengan pelanggan. Customer service center perlu dikelola dengan baik. Petugas tidak hanya menerima order dan menjadi pusat informasi perkertaapian bagi pelanggan, namun juga bertindak sebagai pusat penanganan keluhan pelanggan. Jadi, bukan hanya menerima komplain, tetapi menangani komplain agar di kemudian hari, pelanggan yang tidak puas tidak akan menceritakannya pada orang lain, melainkan memilih mengadu pada PT. KAI. Petugas perlu dilatih agar dapat menangani komplain dengan cepat dan tepat. Untuk itu, perlu dibuat prosedur operasi standar untuk penanganan komplain.

(c) Service Encounter, yang mestinya berlangsung "... every time a customer interact with the service organization" (Zeithaml dan

Tabel 1

“Elements of Physical Evidence"

\begin{tabular}{|l|l|}
\hline \multicolumn{1}{|c|}{ Servicescape } & \multicolumn{1}{c|}{ Other Tangibles } \\
\hline Facility exterior & Other Tangibles \\
Exterior design & Business cards \\
Signage & Stationery \\
Parking & Billing statemnets \\
Landscape & Reports \\
Surrounding environment & Employee dress \\
Facility interior & Uniforms \\
Interior design & Brochures \\
Equipment & Web pages \\
Signage & Virtual servicescape \\
Layout & \\
Air quality/ temperature & \\
\hline
\end{tabular}

Sumber: Zeithaml dan Bitner, (2003) 
Bitner, 2003: 47). Ada tiga tipe service encounters, yaitu: remote encounters, phone encounters, dan face-to-face encounter. Pada remote encounters, pertemuan dapat terjadi tanpa kontak langsung dengan individu, seperti ketika pelanggan berinteraksi dengan bank via ATM. Phone encounters merupakan tipe pertemuan antara pelanggan dan karyawan melalui telepon. Sedangkan faceto-face encounter terjadi jika karyawan dan pelanggan melakukan kontak langsung. Pertemuan antara jasa yang disediakan PT. KAI dengan pelanggan perlu ditata dengan baik. Apalagi dengan adanya berbagai teknologi informasi yang digunakan oleh PT. KAI seperti penggunaan Internet untuk ticketing dan fasilitas layanan pesan-antar. Ke depan, bahkan ada kemungkinan pengembangan ticketing melalui jaringan ATM. Hal ini perlu pengelolaan yang serius dan terintegrasi, sebab di sini awal pertemuan jasa terjadi.

(d) Servicescape. Jasa yang tidak berwujud menyebabkan pelanggan memercayai sejumlah petunjuk yang tangible atau physical evidence, untuk mengevaluasi jasa sebelum dikonsumsi, sekaligus untuk menilai kepuasan selama dan setelah jasa dikonsumsi. Secara umum, bukti fisik dapat dilihat pada tabel berikut ini. Pada Tabel 1, diperlihatkan servicescape (fasilitas fisik) sebagai bentuk dari komunikasi yang berwujud.

Elemen-elemen yang memengaruhi pelanggan melibatkan atribut eksterior (seperti signage, parking, dan landscape) dan atribut interior seperti desain, layout, perlengkapan, dan dekorasi). Sebagai catatan, web pages dan virtual servicescapes disampaikan melalui Internet, tempat perusahaan dapat mengomunikasikan pengalaman jasanya, hingga membuat jasa lebih berwujud kepada pelanggan, baik sebelum atau sesudah pembelian.

Servicescape perlu dikelola dengan baik. Kenyamanan selama perjalanan merupakan sesuatu yang perlu dipertaruhkan, untuk memastikan bahwa pelanggan akan mengulang pembeliannya. Servicescape bukan hanya pada saat perjalanannya. Stasiun-stasiun yang ada juga perlu pembenahan. Bukti-bukti fisik ini menunjukkan sejauhmana PT. KAI mengelola jasanya secara profesional. Pelanggan acap menarik kesimpulan atas jasa yang akan mereka dapatkan, hanya dengan melihat fasilitas dan bukti fisik yang ada.

\section{(3) Internal Marketing Communication.}

(a) Vertical communication, yaitu komunikasi antara karyawan dan perusahaan dalam rangka persetujuan tentang apa yang disampaikan kepada pelanggan

(b) Horizontal Communication, yang merupakan komunikasi antardepartemen dan areaarea dalam perusahaan.

Dalam kegiatan internal marketing communication, di mana terjadi komunikasi vertikal dan horizontal, maka aspek yang perlu diperhatikan adalah karyawan sebagai penyedia jasa. Dalam pemasaran jasa, kepuasan tidak saja pada pihak pelanggan, tetapi juga harus diperoleh karyawan, karena dapat memengaruhi pertumbuhan revenue dan profitabilitas perusahaan. The Service Profit Chain disajikan pada Gambar 2.

Komunikasi pemasaran internal sangat penting dikelola. Kepuasan karyawan akan menjadi titik awal bagaimana 'wajah' pelayanan yang akan diberikan pada pelanggan. Kualitas pelayanan internal PT. KAI akan memengaruhi kepuasan karyawan, yang pada akhirnya berpengaruh pada produktivitas dan retensi karyawan. Pada gilirannya kelak, hal ini juga bakal memengaruhi pelayanan terhadap pelangggan. Pelanggan yang puas dan loyal tentu akan menjadikan PT. KAI berkembang dan mendapatkan profitabilitas yang tinggi.

Oleh karena itu, dalam rangka peningkatan profitabilitas, PT.KAI harus mengomunikasikan jasanya bukan hanya pada pelanggan, namun juga harus dikomunikasikan pada karyawan. Sebab, kepuasan pelanggan pada jasa yang disediakan sangat dipengaruhi bagaimana dan oleh siapa jasa itu disampaikan.

\section{Bagaiman Membangun Komunikasi Pemasaran Jasa yang Efektif?}

Menurut Zeithaml dan Bitner (2003: 449) 
Terakreditasi Dirjen Dikti SK No. 56/DIKTI/Kep/2005

langkah-langkah membangun komunikasi pemasaran jasa yang efektif terdiri dari:

(1) Select the target audience. Dalam setiap kegiatan komunikasi pemasaran, PT. KAI perlu memperhatikan siapa yang menjadi pelanggan potensial, pengguna kereta api saat ini, dan siapa pun yang dapat memengaruhi keputusan pembeli untuk menggunakan jasa PT. KAI.

(2) Determine the communication objectives. Tujuan kegiatan komunikasi pemasaran yang dilakukan PT. KAI perlu melibatkan berbagai aspek psikologis calon pengguna maupun pengguna jasa kereta api, seperti tujuan untuk meningkatkan kesadaran, pengetahuan, kesukaan, preferensi, keyakinan, atau pembelian.

(3) Decide on a budget. Kegiatan komunikasi pemasaran yang dilakukan PT. KAI perlu disesuaikan dengan anggaran yang ada. Alokasi setiap jenis promosi perlu diketahui dengan pasti dan dihitung secara seksama. Sebagai perusahaan yang juga berorientasi bisnis, PT. KAI perlu memperhitungkan profitabilitas yang akan diperoleh, jika sebuah kegiatan komunikasi pemasaran dilakukan.

(4) Create a massage. Pesan komunikasi pemasaran ynag dilakukan PT. KAI melibatkan apa yang akan dikatakan, bagaimana mengatakannya, dan kepada siapa pesan itu akan dikirimkan. Dalam setiap kegiatan komunikasi pemasarannya perlu diusung sebuah tema yang akan ditancapkan pada benak pelanggan. Misalnya, service excellence. Pesan dapat berupa pesan verbal (ujaran atau tulisan), nonverbal (fotografi, ilustrasi, logo atau simbol), atau kombinasi keduanya.

(5) Collect feedback. Setiap kegiatan komunikasi pemasaran yang dilakukan PT. KAI harus selalu dievaluasi. Evaluasi ini melibatkan pencarian kembali bagaimana efektivitas komunikasi dibandingkan dengan tujuan yang ingin dicapai. Feedback merupakan komponen penting dalam kegiatan komunikasi pemasaran jasa. Dengan mengatahui feedback, pengirim pesan akan mengetahui apakah pesan yang disampaikannya memperkuat informasi yang sudah ada, mengubah pesan yang telah sampai kepada konsumen, atau memodifikasi pesan yang telah diterima konsumen. Feedback lebih mudah dipahami dalam kegiatan komunikasi interpersonal. Misalnya, sales-

Gambar 2

The Service Profit Chain

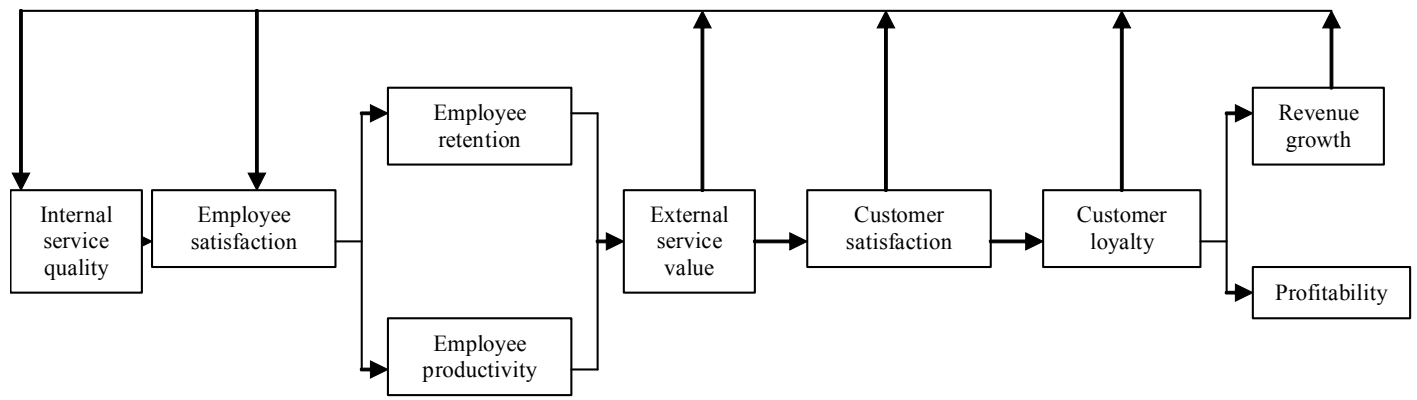

Sumber: J. L Heskett, T.O. Jones, G.W. Loveman, W.E. Sasser, Jr., dan L.A. Schlesinger, (1994)

Prima Mulyasari Agustini. Kompetisi Industri Transportasi: Tinjauan Komunikasi Pemasaran ... 
man dapat melihat feedback dari ekspresi wajah konsumen atau gerakan tubuhnya. Sementara itu, untuk kegiatan komunikasi pemasaran jasa melalui media massa, feedbacknya sulit diketahui. PT. KAI dapat mengetahuinya dengan melakukan riset kepada konsumen/pelanggan. Misalnya, lewat advertising effectiveness research.

\section{Komunikasi Pemasaran Jasa Terpadu}

Saat ini, perusahaan jasa biasanya mengadopsi Integrated Marketing Communications (IMC), yang hanya mengintegrasikan saluran komunikasi eksternal. IMC untuk jasa lebih kompleks ketimbang barang. Dalam Integrated Service Marketing Communications (ISMC), komunikasi tidak saja melalui integrasi saluran eksternal, namun melibatkan pula komunikasi pemasaran melalui saluran internal dan komunikasi pemasaran interaktif, guna memroduksi jasa yang dijanjikan kepada pelanggan. Oleh karena itu, saluran komunikasi pemasaran internal harus dikelola, sehingga karyawan dan PT KAI bersepakat dengan hal-hal yang dapat dikomunikasikan kepada pelanggan. ISMC mensyaratkan agar setiap orang terlibat dengan komunikasi yang jelas, serta memiliki pemahaman antara strategi pemasaran perusahaan dan janjinya kepada konsumen.

Zeithaml dan Bitner merinci empat pendekatan untuk Integrated Service Marketing Communications (2003: 459), yakni:

(1) Manage service promises, melibatkan integrasi mengenai janji yang dibuat oleh PT. KAI dalam komunikasi pemasaran eksternal dan pemasaran interaktif untuk memastikan bahwa PT. KAI konsisten dengan janjinya, juga dapat merealisasikannya.

(2) Manage customer expectations, menjelaskan kepada pelanggan bahwa PT. KAI tidak selalu dapat menyediakan level jasa yang diharapkan. Jasa yang diberikan perlu dinegosiasikan dengan ekspektasi pelanggan yang tidak realistis. Untuk itu, kriteria pelayanan yang diberikan PT KAI kepada pelanggan perlu dikomunikasikan.

(3) Improve customer education, dengan cara menyediakan informasi tentang proses jasa dan kriteria evaluatif mengenai aspek penting dalam jasa. PT. KAI perlu mengonfirmasikan performa standar jasanya, mngklasifikasi harapan setelah penjualan, dan mendidik pelanggan untuk menghindari periode sibuk, dan berpindah ke periode tidak sibuk, sehingga pelayanan sesuai standar dapat diberikan.

(4) Manage internal marketing communication. Internal marketing communication dapat dilakukan secara vertikal maupun horizontal. Komunikasi vertikal melibatkan downward communication, dari manajemen ke karyawan; dan upward communications yaitu komunikasi antarfungsi dalam PT. KAI.

\section{Kesimpulan}

PT Kereta Api Indonesia merupakan aset negara yang perlu dikembangkan. Perkembangan PT KAI sangat dipengaruhi oleh peta kompetisi yang terjadi dalam industri transportasi di tanah air. Namunm peta industri transportasi masa kini memperlihatkan, perkembangan industri penerbangan dan angkutan darat lainnya telah mengancam posisi PT KAI, berhubung pelanggan potensial kereta api mulai digerogoti oleh jasa transportasi lain. Ini terutama terlihat pada kasus maskapai penerbangan rute Jakarta-Surabaya, dan travel rute Jakarta-Bandung melalui Tol Cipularang.

Agar tetap survive di tengah kompetisi ini, pemerintah tampaknya perlu melalukan deregulasi di bidang perkeretaapian dengan membuka kran bagi pihak swasta untuk meramaikan industri ini. Dengan demikian, pelanggan akan memiliki pilihan yang lebih beragam, ketika akan menggunakan jasa kereta api.

Agar dapat merebut kembali kejayaan yang dulu pernah dinikmati, sebagai alat transportasi yang didambakan masyarakat, maka PT. KAI perlu berbenah, baik secara internal maupun eksternal. Salah satu pembenahan yang perlu dilakukan adalah cara mengomunikasikan jasa yang 
disediakan PT KAI. Hal ini berkaitan dengan komunikasi pemasaran jasa PT KAI, yang meliputi:

(1) Komunikasi Pemasaran Eksternal (External Marketing Communication) yang melibatkan saluran komunikasi tradisional, seperti advertising, sales promotion, public relations, dan direct marketing.

(2) Komunikasi Pemasaran Internal (Internal Marketing Communication): yang dapat dilakukan dengan dua cara, yaitu vertikal communication dan horizontal communication.

(3) Pemasaran Interaktif (Interactive Marketing Communication), melibatkan pesan dari karyawan yang diberikan kepada pelanggan melalui saluran seperti personal selling, interaksi customer service, interaksi service encounter, dan servicescape.

Dalam upaya optimasi komunikasi pemasaran jasa perkeretaapian PT KAI, aktivitas ini perlu dilakukan secara terpadu. Integrated Service Marketing Communication (ISMC) PT. KAI melibatkan integrasi mengenai janji yang dibuat oleh PT. KAI dalam komunikasi pemasaran eksternal dan pemasaran interaktif, pengelolaan harapan pelanggan, menyediakan informasi tentang proses jasa dan kriteria evaluatif mengenai aspek penting dalam jasa, serta pengelolaan komunikasi pemasaran internal.***

\section{Daftar Pustaka}

Andreassen, Tor William dan Bodil Lindestead. "Customers Loyalty and Complex Services." International Journal of Service Management, Vol.9, No. 1 Hal 7-33.

Asto S. Subroto. "Dari Mana Asalnya Loyalitas Konsumen?” Majalah SWA Sembada No. 02/ XXI/ 19 Januari-2 Februari 2005.

Case Center Departemen Manajemen Fakultas Ekonomi Universitas Indonesia. 2006. Case in Management-Indonesian's Real Companies. Jakarta: Penerbit Salemba Empat.

Heskett, James L. Sasser Jr, W. Earl., dan Schlengsinger. 1997. The Service Profit Chain. USA: The Press.

Schiffmen, Leon G., \& Leslie Lazar Kanuk. 2004. Consumer Behavior (5th Ed.). USA: PrenticeHall, Pearson Education, Inc.

Zeithaml, Valerie A, dan M.J. Bitner. 2003. Service Marketing (3rd Edition). USA: McGraw Hill Co, Inc.

Zeithaml, Valerie A., A. Parasuraman and L.L. Berry. 1990. Delivering Quality Service-Balancing Customer Perceptions and Expectations. USA: The Free Press.

www.kereta-api.com Tanggal akses terakhir 
